\title{
Kualitas dan efisiensi tidur yang buruk pada mahasiswa olahraga tahun pertama srata- 1 terhadap pembelajaran gerak
}

\section{The effect of poor sleep quality and efficiency on learning motion of the first-year sports science undergraduate students}

\author{
Nur Faoziyah ${ }^{1}$ dan Suharjana ${ }^{2}$ \\ 1.2Department of Sport Education, Faculty of Sport Science, Universitas Negeri \\ Yogyakarta, Jl. Colombo No.1, Karang Malang, Caturtunggal, Depok, Sleman District, \\ Special Region of Yogyakarta, 55281, Indonesia
}

Received: 8 July 2020; Revised: 23 July 2020; Accepted: 18 August 2020

\begin{abstract}
Abstrak
Penelitian ini bertujuan mengidentifikasi kualitas dan durasi tidur saat pembelajaraan gerak pada mahasiswa keolahragaan Universitas Negeri Yogyakarta. Model penelitian adalah deskriptif kuantitatif dengan subjek mahasiswa olahraga tahun angkatan 2019 program studi IKOR, PKO dan PJKR dengan jumlah sampel 111 responden. Instrumen penelitian ini menggunakan angket Pittsburgh Sleep Quality Index (PSQI) yang disebarkan melalui google form. Batasan masalah yakni: kualitas dan efisiensi tidur terhadap pembelajaran gerak yang dilakukan pada mahasiswa olahraga baru srata 1. Hasil penelitian ini menunjukan 67 responden $(60,3 \%)$ memiliki durasi tidur yang buruk yaitu kurang dari 7 jam dalam 1 hari. Nilai rata-rata keseluruhan responden yang mengalami gangguan tidur yaitu $3,4 \%$. Kualitas tidur yang dirasakan oleh responden pada bulan sebelumnya sebanyak 23 responden $(20,7)$ menyatakan bahwa tidur mereka buruk hingga sangat buruk, sedangkan pada minggu lalu menyatakan bahwa kualitas tidur buruk hingga sangat buruk sebanyak 28 responden (25,2\%). Penurunan dan kurang semangat dalam pembelajaran gerak ketika kurang tidur yaitu 21 responden (18,9\%), sedangkan mengalami sulit konsentrasi dalam pembelajaran gerak ketika kurang tidur yaitu 19 responden $(17,1 \%)$. Hal tersebut membuat responden sering mengalami kesusahan saat melakukan dan mengikuti pembelajaran gerak yaitu sebesar $13,5 \%$. Kesimpulan penelitian ini adanya pengaruh kualitas dan efisiensi tidur yang buruk terhadap pembelajaran gerak.
\end{abstract}

Kata kunci: kualitas tidur, efisiensi tidur, pembelajaran gerak.

\begin{abstract}
This study aims to identify the quality and duration of sleep when learning motion in sports students at Yogyakarta State University. The model of this research is descriptive quantitative with the subjects of 2019 students of sports science, sports coaching education, and physical education study programs. The total samples are 111 respondents. The research instrument employs Pittsburgh Sleep Quality Index (PSQI) questionnaire distributed via google form. The limitation of the problem covers sleep quality and efficiency on first year undergraduate students while learning motion. The result shows that 67 respondents (60.3\%) have poor sleep quality of less than 7 hours sleep duration in a day. The average value of all respondents who experience sleep disturbances is $3.4 \%$. 23 respondents (20.7) measure their quality of sleep in the
\end{abstract}

Correspondence author: Nur Faoziyah, Universitas Negeri Yogyakarta, Indonesia.

Email: nurfaoziyahceoa21@gmail.com 
previous month as bad to very bad, while 28 respondents (25.2\%) state their quality of sleep last week as bad to very bad. Due to lack of sleep, 21 respondents (18.9\%) experience a decrease and lack of enthusiasm in learning motion and 19 respondents (17.1\%) experience difficulty in concentrating. This makes respondents often experience difficulties to perform and follow the exercise, which is equal to $13.5 \%$. The conclusion of this study is poor sleep quality and efficiency influence learning motion.

Keywords: sleep quality, sleep efficiency, learning motion.

\section{PENDAHULUAN}

Tidur merupakan proses istirahat secara alami, dimana suatu kondisi berada dibawah alam bawah sadar akan tetapi masih bisa dibangunkan dengan adanya rangsang. Faktanya individu atau seseorang menghabiskan sepertiga hidupnya untuk tidur. Tidur mempunyai dampak yang baik untuk kesehatan tubuh dan apabila kekurngan akn berdampak negatif pada kesehatan. Gangguan tidur selama bertahun-tahun menjadi masalah kesehatan yang terus meningkat (Hirshkowitz et al., 2015).

Tahun pertama merupakan masa transisi bagi mahasiswa baru, dari lingkungan, sosial, dan kehidupan kampus yang baru. Yang menyebabkan 60\% mahasiswa melaporkan bahwa mereka mempunyai kualitas tidur yang buruk (Lund, Reider, Whiting, \& Prichard, 2010), tingkat stres yang terjadi pada mahasiswa termasuk tinggi (Hunt \& Eisenberg, 2010). Penelitian lain menunjukan bahwa aktivitas sosial, lingkungan yang kurang kondusif membuat mahasiswa juga mempengaruhi durasi tidur mahasiswa (Knowlden, Sharma, \& Bernard, 2012; Pedersen et al., 2008). Survei nasional yang dilakukan pada mahasiswa berkaitan dengan dampak kualitas tidur dikaitkan dengan nilai prestasi akademik atau IPK mempunyai efek terhadap pencapaian IPK yang rendah, yang terjadi pada peningkatan masalah tidur pada mahasiswa (Hartmann \& Prichard, 2018).

Diketahui bahwa tidur sangat penting untuk kesehatan tubuh secara menyeluruh (Paruthi et al., 2016). Kurang tidur atau kualitas tidur yang buruk akan berdampak negatif kepada kesehatan, termasuk kesehatan mental seperti depresi, khawatir, cemas (Chaput et al., 2016; Freeman et al., 2017; Medic, Wille, \& Hemels, 2017; Shochat, CohenZion, \& Tzischinsky, 2014), terjadinya ganguan fungsi fisiologi tubuh 
seperti gangguan motorik, gangguan kognitif, emosi, performa saat olahraga dan berpeluang meningkatkan resiko terjadinya cidera, penggunaan narkoba, pola makan yang buruk, obesitas, prestasi akademik yang kurang baik, hingga penggunaan narkoba (Anderson, Storfer-Isser, Taylor, Rosen, \& Redline, 2009; Chaput et al., 2016; Khan, Chu, Kirk, \& Veugelers, 2015; Shochat et al., 2014), penyimpangan perhatian (Heaton, Maule, Maruta, Kryskow, \& Ghajar, 2014; Renn \& Cote, 2013). Kekurangan tidur akan berdampak pada peningkatan rasa ngantuk dan gangguan kognitif (Babkoff, Caspy, \& Mikulincer, 1991), selain itu juga ditemukan bahwa jam tidur yang kurang akan berdampak pada metabolisme, fungsi endokrin, meningkatkan pengeluaran energi yang berlebihan saat latihan, menggurangi tingkat performa atau hasil kinerja (Spiegel, Leproult, \& Van Cauter, 1999). Dampak negatif dari kekurangan tidur akan mempengaruhi keterampilan, kekuatan submaksimal dan kekuatan otot (Fullagar et al., 2015).

Tidur yang direkomendasi untuk orang dewasa yaitu kurang lebih 7 jam permalam, hal tersebut berfungsi untuk meningkatkan kesehatan dan performa yang bagus (Watson et al., 2015a). Karena tidur memainkan peran penting dalam proses kognitif serta kesehatan mental dan fisik. Meskipun pada penelitian-penelitian sebelumnya diketahui bahwa mahasiswa keolahragaan pada perguruan tinggi terbiasa tidur kurang dari 7 jam permalam (Lund et al., 2010; Mah, Kezirian, Marcello, \& Dement, 2018). Bukti lain menunjukan pada atlet kriket dan rugby diketahui memiliki kualitas tidur yang buruk dan memiliki tingkat kantuk yang berat saat siang hari (Swinbourne et al., 2015), atlet perorangan dan team Jerman dan Australia melaporkan adanya gangguan tidur dan kurang tidur sebelum pertandingan (Erlacher, Ehrlenspiel, Adegbesan, \& El-Din, 2011; Juliff, Halson, \& Peiffer, 2014). Konsekuensi kurang tidur bagi orang dewasa khususnya mahasiswa keolahragaan seharusnya menjadi perhatian besar, karena dampak yang ditimbulkan sangat merugikan. Karena pengaruh tidur pada sistem kekebalan tubuh (Segerstrom \& Miller, 2004). Tingkat pelatihan pada cabang olahraga tertentu dapat 
mempengaruhi kebutuhan tidur (Paruthi et al., 2016). Pengetahuan tentang kesehatan tidur yang didalamnya meliputi durasi atau waktu, kualitas dalam konteks fisik, psikologis, emosional masih minim.

Pada penelitian ini memaparkan tentang kualitas tidur dan efisiensi tidur pada mahasiswa terhadap pembelajaran gerak. Sedangkan penelitan yang di paragraf sebelumnya memaparkan dampak kekurangan tidur pada kesehatan seperti fisiologi tubuh, emosi, obesitas, metabolisme, fungsi endokrin. Selain itu pula pada penelitian sebelumnya ditemukan bahwa dampak negatif dari kekurangan tidur akan mempengaruhi keterampilan, kekuatan submaksimal dan kekuatan otot. Dampak kekurangan tidur juga memiliki tingkat kantuk yang tinggi pada siang hari.

Tujuan dari penelitian ini yaitu mengidentifikasi kesehatan baik kualitas dan durasi tidur saat pembelajaraan gerak pada pada mahasiswa baru atau semester pertama keolahragaan universitas negeri yogyakarta. Oleh karena itu, pada mahasiswa baru dapat diidentifikasi tingkat kecukupan dan efisiensi tidur, pengetahuan tentang tidur dapat membantu dalam mengidentifikasi potensi kecukupan dan efisiensi saat pembelajaran gerak pada universitas lain untuk meningkatkan kualitas tidur, pemulihan, meningkatkan kesehatan mahasiswa olahraga.

\section{METODE}

Penelitian ini mengguanakan metode deskriptip kuantitatif, yaitu metode yang digunakan untuk menggambarkan fenomena yang ada baik berlangsung saat ini ataupun masa lampau. Penelitian deskriptif kuantitatif bertujuan tidak mengadakan manipulasi atau pengubahan pada variable bebas, hal ini menggambarkan suatu kondisi yang apa adanya dalam menjelaskan kondisi tertentu (Morissan, 2012). Penelitian ini menjelaskan bagaimana pengaruh kecukupan tidur terhadap pembelajaran gerak atau pada mata kuliah praktik saat pembelajaran. Tempat dan waktu penelitian yaitu di Yogyakarta, Penelitian pada 3-22 Februari 2020 dengan jarak durasi 3 minggu setelah penyebaran angket melalui google form dengan daftar pertanyaan mengguanakan Pittsburgh Sleep Quality Index (PSQI). 
Populasi pada penelitian ini adalah mahasiswa olahraga angkatan 2019, sampel dengan kriteria jurusan PKO, IKOR, dan PJKR sebanyak 453 mahasiswa. Untuk menentukan informan, maka peniliti menggunakan pengambilan sampel secara random sampling.

Pengolahan data diawali dengan editing untuk mengecek kelengkapan data, cooding untuk memudahkan dalam proses pemasukan data, selanjutnya dilakukan proses entri data dengan menggunakan SPSS.

\section{HASIL}

Populasi pada penelitian ini berasal dari mahasiswa keolahragaan universitas negeri yogyakarta, angkatan masuk tahun 2019. Total jumlah peserta terdapat 111 responden dari 3 jurusan yaitu PKO, IKOR, dan PJKR dengan total jenis kelamin 73 laki-laki, 38 perempuan, dengan rentang umur 17,18,19, dan 20 tahun.

Tabel 1. Data Peserta

\begin{tabular}{|c|c|c|c|}
\hline & $\begin{array}{l}\text { Total } \\
\text { N\% }\end{array}$ & $\begin{array}{c}\text { Laki-laki } \\
\text { N\% }\end{array}$ & $\begin{array}{c}\text { Perempuan } \\
\mathrm{N} \%\end{array}$ \\
\hline Peserta & $111(100 \%)$ & $73(65,7 \%)$ & $38(34,2 \%)$ \\
\hline Jurusan & $3(100 \%)$ & $70(63,1 \%)$ & $38(34,2 \%)$ \\
\hline PKO & $30(27 \%)$ & $22(73,3 \%)$ & $8(26,6 \%)$ \\
\hline IKOR & $36(32,4 \%)$ & $24(66,6 \%)$ & $12(33,3 \%)$ \\
\hline PJKR & $45(40,5)$ & $27(60 \%)$ & $18(40 \%)$ \\
\hline \multicolumn{4}{|l|}{ Umur } \\
\hline 17 & 7 (6,3\%) & $4(57,15 \%)$ & $3(42,85 \%)$ \\
\hline 18 & $61(54,9 \%)$ & $41(67,25 \%)$ & $20(32,75 \%)$ \\
\hline 19 & $37(33,3 \%)$ & $22(59,45 \%)$ & $15(40,55 \%)$ \\
\hline 20 & $6(5,4 \%)$ & $3(50,0 \%)$ & $3(50,0 \%)$ \\
\hline
\end{tabular}

Jam Tidur

Jam tidur yang dimiliki oleh peserta dari jam tidur malam, jumlah hari untuk tidur siang dalam seminggu, durasi tidur siang, dan total tidur dalam sehari. Dalam penelitian ini responden melaporkan jam tidur malam bahwa tidur pukul $\leq 21.00$ (7,2\%), pukul 21.00-22.00 (25,2\%), 22.01-23.00 $(34,2 \%)$, pukul 23.01-24.00 (25,4\%), dan $\geq 00.00 /$ dini hari (14,4\%). Jumlah hari untuk tidur siang dalam seminggu melaporkan bahwa tidak pernah (10,8\%), 1-2 hari (42,3\%), 3-4 hari (34,2\%), 5-6 hari (6,3\%), dan setiap hari $(5,4 \%)$. Durasi ketika tidur siang mereka melaporkan tidak ada 
$(11,7 \%), \leq 10$ menit $(3,6 \%), 10-30$ menit $(27,0 \%), 31-60$ menit $(21,6 \%), \geq$ 1 jam (36,0\%). Total rata-rata jam tidur per hari yang dilakukan responden menyatakan bahwa tidur $\leq 5$ jam (6,3\%), 5,1-6 jam (23,4\%), 6,1-7 jam

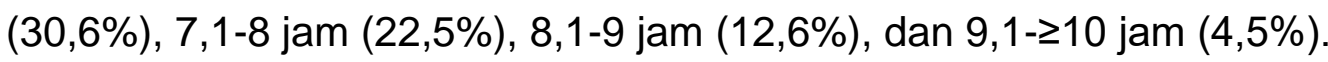

\section{Gangguan Tidur}

Responden menyatakan adanya gangguan tidur pada malam hari seperti tidak mampu tertidur selama 30 menit sejak berbaring, terbangun ditengah malam, sulit bernafas dengan leluasa, batuk atau mendengkur, suhu dimalam hari, mimpi buruk, nyeri badan, lapar, bergadang dan alasan lain menunjukan rata nilai per responden yaitu dengan kategori tidak pernah $(1,7 \%)$, jarang $(41,9 \%)$, kadang-kadang $(51 \%)$, sering $(4,4 \%)$, setiap hari $(0,8 \%)$ dengan rata nilai keseluran yaitu $3,4 \%$.

\section{Alat Bantu Tidur}

Ketika menuju tidur responden membutuhkan alat bantu tidur yaitu setiap hari $(1,8 \%)$, sering $(4,5 \%)$, kadang-kadang $(30,6)$, jarang $(16,2 \%)$, tidak sama sekali $(46,8 \%)$.

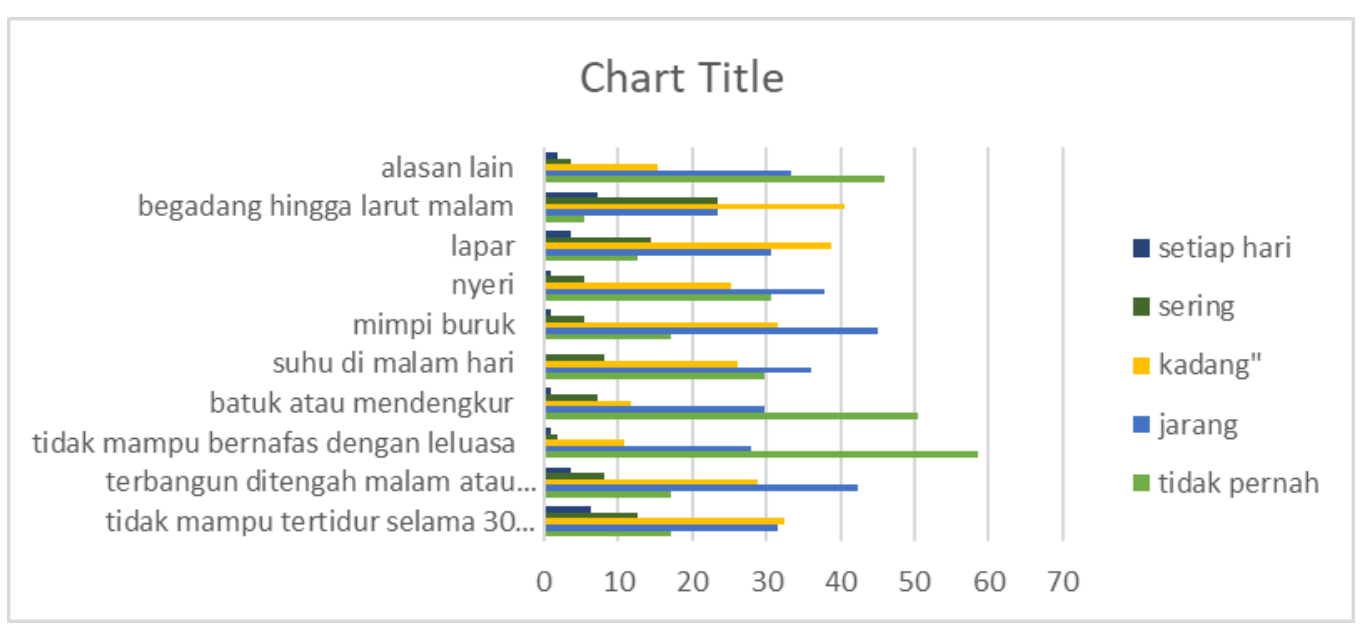

Gambar 1. Faktor-faktor yang Mempengaruhi Kualitas Tidur Pada Malam Hari.

\section{Kualitas tidur}

Kualitas bulan dan minggu lalu menyatakan bahwa responden yaitu pada bulan lalu menyatakan sangat buruk $(3,6 \%)$, buruk $(17,1 \%)$, sedang $(52,2 \%)$, baik $(25,2 \%)$, sangat baik $(1,8 \%)$. Sedagkan untuk minggu lalu 
responden mengungkapkan bahwa sangat buruk $(2,7 \%)$, buruk $(22,5 \%)$, sedang $(46,8 \%)$, baik $(26,1 \%)$, sangat baik $(1,8 \%)$.

\section{Pembelajaran Gerak}

Responden menyatakan bahwa mengalami penurunan dan kurang semangat dalam pembelajaran gerak yaitu tidak pernah $(5,4 \%)$, jarang $(24,3 \%)$, kadang-kadang (51,3\%), sering (18,0\%), setiap pembelajaran $(0,9 \%)$. Sulit konsentrasi dalam pembelajaran gerak yaitu tidak pernah $(10,8 \%)$, jarang $(27,0 \%)$, kadang-kadang $(44,1 \%)$, sering $(15,3 \%)$, setiap pembelajaran $(2,7 \%)$.

\section{Faktor Intriksik dan Ekstrinsik yang Membuat Kurang Bersemangat dan Sulit Konsentrasi Dalam Pembelajaran Gerak}
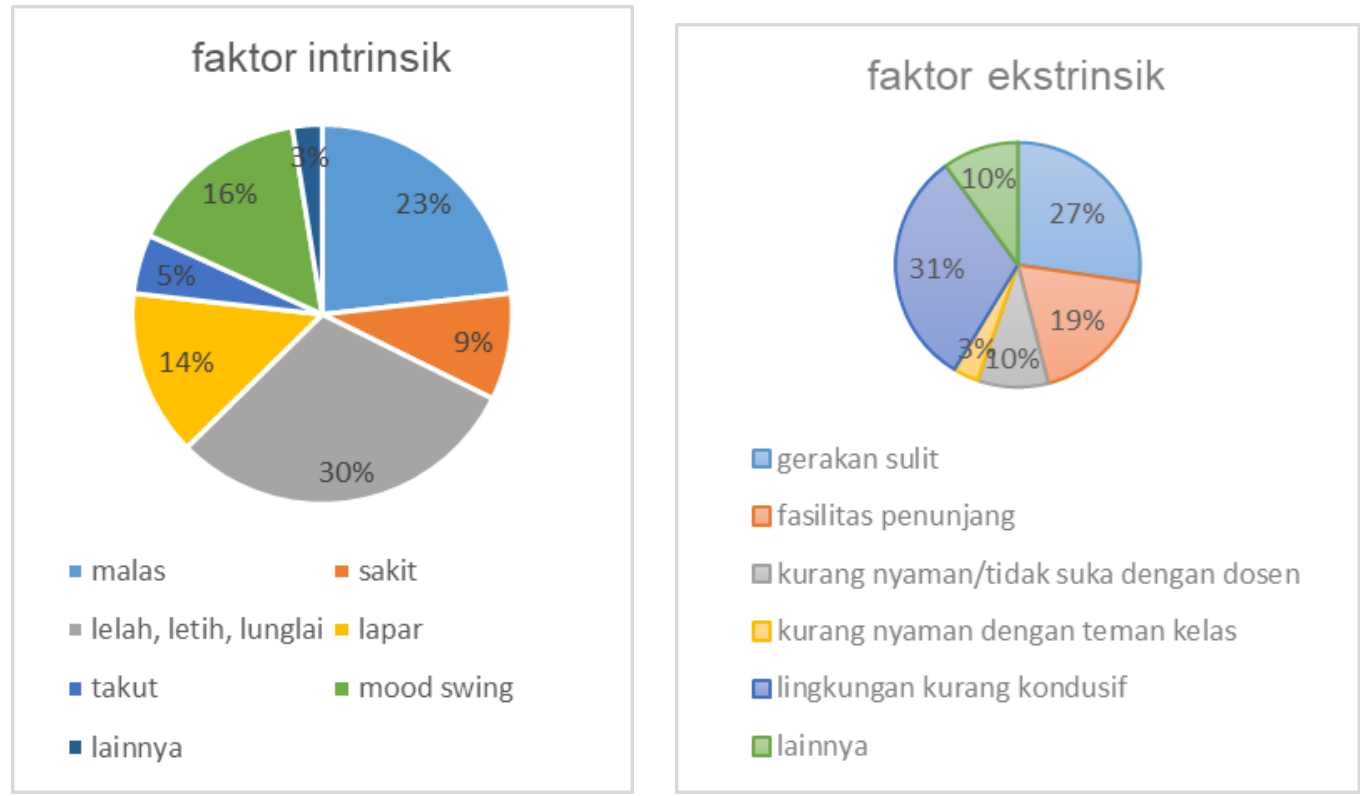

Gambar 2. Faktor Intrinsik dan Faktor Ekstrinsik

\section{Kesusahan saat melakukan dan mengikuti gerakan olahraga dalam mata kuliah praktek}

Responden menyatakan tingkat kesusahan dan mengikuti gerakan dalam pembelajaran gerak menyatakan bahwa: tidak pernah $(10,8 \%)$, jarang $(33,3 \%)$, kadang-kadang $(42,3 \%)$, Sering (13,5\%), Setiap hari $(0 \%)$. 


\section{PEMBAHASAN}

Penelitian ini meneliti mahasiswa olahraga untuk menilai durasi tidur, kualitas tidur, terhadap pembelajaran gerak. Hasil yang ada menyatakan bahwa kualitas tidur mahasiswa baru buruk memiliki implikasi penting yang berpotensi mengganggu fisiologis, kesehatan fisik dan mental, meningkatkan resiko cedera, dan mengganggu kinerja. Penelitian ini menemukan bahwa 67 responden dari 111 mengalami durasi tidur yang kurang baik yaitu tidur kurang dari 7 jam perhari (Watson et al., 2015b), dengan bukti lain yang menunjukan mahasiswa olahraga memiliki jam tidur yang kurang (Lund et al., 2010). Kualitas tidur yang dirasakan oleh responden pada bulan lalu 23 responden (20,7\%) menyatakan bahwa tidur mereka buruk-sangat buruk, sedangkan pada minggu lalu menyatakan dengan hal yang sama dengan kualitas tidur buruk- sangat buruk sebanyak 28 responden $(25,2 \%)$.

Kurang tidur mengakibatkan terjadinya ganguan motorik, gangguan kognitif, emosi, prestasi akademik, pola makan yang buruk dan performa saat olahraga (Anderson et al., 2009; Khan et al., 2015; Medic et al., 2017; Shochat et al., 2014), dalam penelitian ini menunjukan bahwa adanya penurunan dan kurang semangat dalam pembelajaran gerak ketika kurang tidur yaitu 21 responden (18,9\%), sedangkan mengalami sulit konsentrasi dalam pembelajaran gerak ketika kurang tidur yaitu 19 responden $(17,1 \%)$. Hal tersebut membuat responden sering mengalami kesusahan saat melakukan dan mengikuti pembelajaran gerak yaitu sebesar 13,5\%. Dikarenakan adanya gangguan pada diri responden seperti rasa malas (23\%), lelah, letih, lesu (30\%), sakit (9\%), lapar (14\%), mood swing (16\%). Selain adanya faktor intriksik yang berpengaruh terhadap pembelajaran terdapat faktor ekstrinsik yang mempengaruhi pembelajaran seperti fasilitas penunjang (19\%), lingkungan kurang kondusif (31\%), kurang nyaman dengan teman sekelas (3\%), kurang nyaman atau tidak suka dengan dosen (9\%) dan gerakan sulit $(28 \%)$. 
Jam tidur yang kurang secara terus menurus memiliki implikasi besar terhadap potensi cidera (Luke et al., 2011), dan kerentanan terhadap penyakit menular (Prather, Janicki-Deverts, Hall, \& Cohen, 2015). Temuan pada penelitian ini menunjukan tingginya tingkat prevalensi tidur siang rutin, dengan presentase $88,2 \%$ meskipun hanya 1 2 hari dalam seminggu. Tidur siang pendek dapat memberikan manfaat kinerja dan memiliki implikasi ke kebugaran. Kurang tidur berdampak pada psikologis, yang mempengaruhi interpretasi emosional dan psikososial yang dapat memperburuk tingkat stress yang cenderung untuk memilih dan mengingat ingatan negatif setelah kurang tidur (Stickgold \& Walker, 2013). Hal tersebut yang membuat tubuh terdapat adanya rasa malas, lelah, letih, lesu, sakit dan mood swing.

\section{KESIMPULAN}

Penelitaian ini menunjukan adanya kualitas tidur yang buruk pada mahasiswa olahraga Universitas Negeri Yogyakarta yang memiliki implikasi menyebabkan pengaruh terhadap pembelajaran gerak. Adanya penurunan dan kurang semangat, serta sulit konsentrasi saat pembelajaran. Akibat kurang tidur menyebabkan rasa malas, lelah, letih, lesu, sakit, lapar, dan mood swing.

\section{REFERENSI}

Anderson, B., Storfer-Isser, A., Taylor, H. G., Rosen, C. L., \& Redline, S. (2009). Associations of executive function with sleepiness and sleep duration in adolescents. Pediatrics, 123(4), 701-707. https://doi.org/10.1542/peds.2008-1182

Babkoff, H., Caspy, T., \& Mikulincer, M. (1991). Subjective sleepiness ratings: The effects of sleep deprivation, circadian rhythmicity and cognitive performance. Sleep, 14(6), 534-539. https://doi.org/10.1093/sleep/14.6.534

Chaput, J., Gray, C. E., Poitras, V. J., Carson, V., Gruber, R., Olds, T., Tremblay, M. S. (2016). Systematic review of the relationships between sleep duration and health indicators in school-aged children and youth. Appl. Physiol. Nutr. Metab, 41(June), 266-282. https://doi.org/10.1139/apnm-2015-0627

Erlacher, D., Ehrlenspiel, F., Adegbesan, O. A., \& El-Din, H. G. (2011). Sleep habits in German athletes before important competitions or 
games. Journal of Sports Sciences, 29(8), 859-866. https://doi.org/10.1080/02640414.2011.565782

Freeman, D., Sheaves, B., Goodwin, G. M., Yu, L. M., Nickless, A., Harrison, P. J., Espie, C. A. (2017). The effects of improving sleep on mental health (OASIS): a randomised controlled trial with mediation analysis. The Lancet Psychiatry, 1-10. https://doi.org/10.1016/S2215-0366(17)30328-0

Fullagar, H. H. K., Skorski, S., Duffield, R., Hammes, D., Coutts, A. J., \& Meyer, T. (2015). Sleep and Athletic Performance: The Effects of Sleep Loss on Exercise Performance, and Physiological and Cognitive Responses to Exercise. Sports Medicine, 45, 161-186. https://doi.org/10.1007/s40279-014-0260-0

Hartmann, M. E., \& Prichard, J. R. (2018). Calculating the contribution of sleep problems to undergraduates' academic success. Sleep Health, 4, 463-471. https://doi.org/10.1016/j.sleh.2018.07.002

Heaton, K. J., Maule, A. L., Maruta, J., Kryskow, E. M., \& Ghajar, J. (2014). Attention and visual tracking degradation during acute sleep deprivation in a military sample. Aviation Space and Environmental Medicine, 85(5), 497-503. https://doi.org/10.3357/ASEM.3882.2014

Hirshkowitz, M., Whiton, K., Albert, S. M., Alessi, C., Bruni, O., DonCarlos, L., Ware, J. C. (2015). National Sleep Foundation's updated sleep duration recommendations: Final report. Sleep Health, 1(4), 233243. https://doi.org/10.1016/j.sleh.2015.10.004

Hunt, J., \& Eisenberg, D. (2010). Mental Health Problems and HelpSeeking Behavior Among College Students. Journal of Adolescent Health, $46(1)$,

3-10.

https://doi.org/10.1016/j.jadohealth.2009.08.008

Juliff, L. E., Halson, S. L., \& Peiffer, J. J. (2014). Understanding sleep disturbance in athletes prior to important competitions. Journal of Science and Medicine in Sport, 1-6. https://doi.org/10.1016/j.jsams.2014.02.007

Khan, M. K. A., Chu, Y. L., Kirk, S. F. L., \& Veugelers, P. J. (2015). Are sleep duration and sleep quality associated with diet quality, physical activity, and body weight status? A population-based study of Canadian children. Canadian Journal of Public Health, 106(5), e277-e282. https://doi.org/10.17269/CJPH.106.4892

Knowlden, A. P., Sharma, M., \& Bernard, A. L. (2012). A Theory of Planned Behavior Research Model for Predicting the Sleep Intentions and Behaviors of Undergraduate College Students. Journal of Primary Prevention, 33(1), 19-31. https://doi.org/10.1007/s10935-012-0263-2

Luke, A., Lazaro, R. M., Bergeron, M. F., Keyser, L., Benjamin, H., Brenner, J., Smith, A. (2011). Sports-related injuries in youth 
athletes: Is overscheduling a risk factor? Clinical Journal of Sport Medicine, 21(4),

307-314. https://doi.org/10.1097/JSM.0b013e3182218f71

Lund, H. G., Reider, B. D., Whiting, A. B., \& Prichard, J. R. (2010). Sleep Patterns and Predictors of Disturbed Sleep in a Large Population of College Students. Journal of Adolescent Health, 46(2), 124132. https://doi.org/10.1016/j.jadohealth.2009.06.016

Mah, C. D., Kezirian, E. J., Marcello, B. M., \& Dement, W. C. (2018). Poor sleep quality and insuf fi cient sleep of a collegiate student-athlete population. Sleep Health: Journal of the National Sleep Foundation, 60, 251-257. https://doi.org/10.1016/j.sleh.2018.02.005

Medic, G., Wille, M., \& Hemels, M. E. H. (2017). Short- and long-term health consequences of sleep disruption. Nature and Science of Sleep, 9, 151-161. https://doi.org/10.2147/NSS.S134864

Morissan. (2012). Metode Penelitian Survey. Jakarta: Kencana Prenada Media.

Paruthi, S., Brooks, L. J., Ambrosio, C. D., Hall, W. A., Kotagal, S., Lloyd, R. M., Troester, M. M. (2016). Consensus Statement of the American Academy of Sleep Medicine. The Journal of Clinical Sleep Medicine, 12(11), 1549-1561. https://doi.org/http://dx.doi.org/10.5664/jcsm.6288

Pedersen, D. J., Lessard, S. J., Coffey, V. G., Churchley, E. G., Wootton, A. M., Ng, T., Hawley, J. A. (2008). High Rates of Muscle Glycogen Resynthesis After Exhaustive Exercise When Carbohydrate is Coingested With Caffeine. Journal of Applied Physiology, 105, 7-13. https://doi.org/10.1152/japplphysiol.01121.2007

Prather, A. A., Janicki-Deverts, D., Hall, M. H., \& Cohen, S. (2015). Behaviorally Assessed Sleep and Susceptibility to the Common Cold. Sleep, 38(9), 1353-1359. https://doi.org/10.5665/sleep.4968

Renn, R. P., \& Cote, K. A. (2013). Performance monitoring following total sleep deprivation: Effects of task type and error rate. International $\begin{array}{llll}\text { Journal of Psychophysiology, 88, 64-73. } & \text { 88, }\end{array}$ https://doi.org/10.1016/j.jpsycho.2013.01.013

Segerstrom, S. C., \& Miller, G. E. (2004). Psychological stress and the human immune system: A meta-analytic study of 30 years of inquiry. Psychological Bulletin, 130(4), 601-630. https://doi.org/10.1037/0033-2909.130.4.601

Shochat, T., Cohen-Zion, M., \& Tzischinsky, O. (2014). Functional consequences of inadequate sleep in adolescents: Asystematic review. Sleep Medicine Reviews, 1-13. https://doi.org/10.1016/j.smrv.2013.03.005 
Spiegel, K., Leproult, R., \& Van Cauter, E. (1999). Impact of sleep debt on metabolic and endocrine function. Lancet, 354(9188), 1435-1439. https://doi.org/10.1016/S0140-6736(99)01376-8

Stickgold, R., \& Walker, M. P. (2013). Sleep-dependent memory triage: Evolving generalization through selective processing. Nature Neuroscience, 16(2), 139-145. https://doi.org/10.1038/nn.3303

Swinbourne, R., Gill, N., Vaile, J., Smart, D., Swinbourne, R., Gill, N., ... Smart, D. (2015). Prevalence of poor sleep quality, sleepiness and obstructive sleep apnoea risk factors in athletes risk factors in athletes.

https://doi.org/10.1080/17461391.2015.1120781 1391(December).

Watson, N. F., Badr, M. S., Belenky, G., Bliwise, D. L., Buxton, O. M., Buysse, D., Heald, J. L. (2015a). Joint Consensus Statement of the American Academy of Sleep Medicine and Sleep Research Society on the Recommended Amount of Sleep for a Healthy Adult: Methodology and Discussion. Journal of Clinical Sleep Medicine, 38(8), 1161-1183. https://doi.org/10.5665/sleep.4886

Watson, N. F., Badr, M. S., Belenky, G., Bliwise, D. L., Buxton, O. M., Buysse, D., Heald, J. L. (2015b). Recommended Amount of Sleep for a Healthy Adult: A Joint Consensus Statement of the American Academy of Sleep Medicine and Sleep Research Society. Journal of Clinical Sleep Medicine, 38(6), 843-844. https://doi.org/10.5665/sleep.4716 